\title{
LETTERS
}

\section{Concise Research Reports \\ Keys to career success: resources and barriers identified by early career academic hospitalists}

\author{
Ethan Cumbler, MD, FHM, FACP ${ }^{7}$, Patrick Rendón, MD², Essey Yirdaw, MPH ${ }^{7}$, Patrick Kneeland, MD ${ }^{7}$, \\ Read Pierce, $M D^{7}$, Christine D. Jones, $M D^{7}$, and Carrie Herzke, MD, SFHM, FAAP, FACP ${ }^{3}$ \\ 'University of Colorado School of Medicine, Aurora, CO, USA; ${ }^{2}$ University of New Mexico, Albuquerque, NM, USA; ${ }^{3}$ Johns Hopkins University School of \\ Medicine, Baltimore, MD, USA.
}

KEY WORDS: faculty development; continuing professional development; qualitative research; mentoring/mentorship; hospital medicine; burnout.

J Gen Intern Med 33(5):588-9

DOI: $10.1007 / \mathrm{s} 11606-018-4336-7$

(C) Society of General Internal Medicine 2018

\section{INTRODUCTION}

Prior research in the field of academic hospital medicine has described challenges to achieving promotion for academic hospitalists. ${ }^{1,2}$ A consensus conference identified barriers for academic hospitalist success including alignment of hospitalists with clinical priorities that may not be recognized for academic advancement, inadequate infrastructure to promote success, and lack of national funding for research in general inpatient medicine. ${ }^{3}$ Research is needed to better understand perspectives of academic hospitalists regarding the pathway to career success. ${ }^{1}$ This qualitative study explores the barriers and facilitators of career success as perceived by early career academic hospitalists.

\section{METHODS}

This was a qualitative descriptive study in which we conducted in-depth interviews facilitated by a semi-structured interview guide. Cognitive interviewing with three representative academic hospitalists was done for face validation of the question probe structure. Interviews with early career academic hospitalists self-identifying as clinician-educators from three academic medical centers were conducted by the primary investigator as part of a study to explore their experiences and perceptions of career success. ${ }^{4}$ All interviews were recorded, de-identified, and transcribed, with auditing for accuracy and completeness. This study was approved by the Colorado Multiple Institution Review Board.

Transcripts of interviews relating to barriers, resources, and hospital medicine group support for success were analyzed for themes using an iterative general inductive approach. Two members of the research team independently reviewed the transcripts and assigned codes to meaningful text segments. A consensus code framework was developed by research team members with codes added, removed, or combined at this stage of the analysis.

Published online February 8, 2018
Each segment of text was then re-coded. Text segments assigned to each code were combined and analyzed to determine themes.

\section{RESULTS}

Seventeen academic clinician-educator hospitalists were interviewed. Subjects had been academic hospitalists an average of 3.1 years, $94 \%$ were assistant professors, $47 \%$ (8/17) were female, and $12 \%$ were underrepresented minorities. Interviews lasted an average of $32 \mathrm{~min}$.

\section{Resources to Find Career Success}

The most common resources identified by early-career hospitalists to facilitate success included protected non-clinical time (Table 1), individual mentorship, and a wide professional network.

"Whatever direction you do as an academic hospitalist... without having someone to show you by example how to do these things... it's almost impossible."

\section{Barriers to Career Success}

The most commonly identified barriers included a lack of protected non-clinical time to devote to academic pursuits, burnout due to excessive work stress, and competing professional responsibilities creating tension between clinical and non-clinical academic priorities.

\section{"That constant battle between the clinical work and the academic work is a real struggle."}

\section{Hospital Medicine Groups' Supporting Success}

Hospitalists most frequently thought the hospital medicine group could support success through facilitating mentorship and providing protected non-clinical time.

"I think building in protected time from day one... makes a world of difference. Because it's not necessarily the time, it's the gesture saying that we know you need the breathing room to figure out who you are, what your interests are, and how to develop these skills." 


\section{Table 1 A Brief Exploration of Time}

Time as necessary for success

Time defined as days protected from clinical duties for other academic work.

Time for exploration

Time protected within the day mitigating conflicting professional roles

Time promoting niche development

Time mitigating burnout

Time supporting work-life balance

Efficient clinical systems as a mechanism to provide time

Time as marker of respect
"Having the time to devote to some of the things that I personally feel I would like to work on to... achieve a higher level of success would be a necessary resource at this point."

"I think time is by far the biggest barrier to success. I think the demands of our clinical job as well as the fact that everything in academics is understaffed and underfunded. This leads to everyone trying to fit three things into a minute instead of one thing into a minute. By and large I am always going to tell you that if you give me more time then I am going to do better.

"Some relief from clinical duties. You know I think when someone is really working every other week. You know 7 days on 7 days, off or 2 weeks on and 2 weeks off, it's really difficult to develop the expertise that would facilitate success as defined by our academic hospitalist culture."

"Having some protected time even from the beginning when you don't necessarily have grant support so that you have time to sort of begin exploring different areas and trying to figure out what would be the right thing to work on."

"Have some sort of protected time, whether that is because I am not working as long during the day or because I am actually protected in some way for a brief period of time to check my email... I would probably provide better patient care because I would not be worried about the competing interest in my mind at that particular moment so I could truly be there for the patient. When I am on a teaching service, which most of the time I am, I could focus on teaching, being a better teacher.

"To allow them to get a foothold into some sort of aspect that they would like to focus in on... By giving people time to work on things and to show their value and then have them figure out a way to fund that work or to demonstrate why it was important to the group and to the University would be a great way to kick start some people's careers."

"Give people that mental time and space to come up with their "thing" maybe faster, prevent burnout a little bit. Even if it was (laughs) a matter of messing with the numbers and saying our full time gig is 19 days a month but we give everybody 2 days for their scholarly FTE. Having everyone feel like they have time to do something."

And then flip it around during whatever protected time and say now I have some set aside space to do my administrative work and by the way I would still be able to eat dinner when I get home and maybe have a conversation with my wife."

"Just to streamline those clinical systems so we are given more time during our normal clinical days to work on other things too. Trying to figure out a way make our social work and case managers work a little more efficiently, trying to make us geographically cohorted, so we can make our rounds go quickly and to communicate better instead of spending so many hours trying to fix the holes and try to plug the holes in the system."

"It says a lot about them as people and what the group thinks about them. To say we believe in you, here's the $10 \%$ because we know you will do great things with this."

\section{DISCUSSION}

The presence, or absence, of protected non-clinical time was a cross-cutting theme and could mitigate burnout and the conflict referenced by early career hospitalists between clinical and non-clinical obligations. Faculty perspectives on importance of time are supported by research demonstrating a positive association between protected time and scholarly productivity. ${ }^{1}$ The concept of "time" as an essential facilitator of career success was complex as highlighted in Table 1. It also encompassed time to focus fully on the delivery of clinical care and time for life outside of work. Mechanisms for the group to maximize time included creating a clinical environment that functioned efficiently as well as administrative support to allow time to be used more effectively.

Our findings also suggest that structures to facilitate individual mentoring and collegial professional networks are key to academic hospitalists' career success. This suggests leadership and should closely attend to the efficacy of both mentorship relationships as well as infrastructure to facilitate connections and collaborations between early career hospitalists and their colleagues. Our findings raise questions about the impact of academic positions without protected time for early career faculty to establish their career trajectory and offer insights into levers for academic medicine groups to utilize that may increase the ability of early career hospitalist faculty to find success.

Acknowledgements: The authors would like to thank the early career academic hospitalists who participated in this study.

Corresponding Author: Ethan Cumbler, MD, FHM, FACP; University of Colorado School of Medicine, Aurora, CO, USA (e-mail: Ethan. Cumbler@ucdenver.edu).

\section{Compliance with ethical standards:}

Conflict of Interest: The authors declare that they do not have a conflict of interest.

\section{REFERENCES}

1. Reid MB, Misky GJ, Harrison RA, Sharpe B, Auerbach A, Glasheen JJ. Mentorship, productivity, and promotion among academic hospitalists. J Gen Intern Med 27(1):23-7.

2. Leykum LK, Parekh VI, Sharpe B, Boonyasai RT, Centor R. Tried and true: a survey of successfully promoted academic hospitalists. Journal of Hospital Medicine. 2011;6:411-415.

3. Flanders SA, Centor B, Weber V, McGinn T, DeSalvo K, Auerback A. Challenges and opportunities in academic hospital medicine: report from the academic hospital medicine summit. J gen Intern Med 2009;24:63641.

4. Cumbler E, Yirdaw E, Kneeland P, Pierce R, Rendon P, Herzke C, Jones CD. What Is Career Success for Academic Hospitalists? A Qualitative Analysis of Early-Career Faculty Perspectives. J Hosp Med. In Press. 